\title{
Copper micromesh-based lightweight transparent conductor with short response time for wearable heaters
}

\author{
Han-Jung Kim and Yoonkap Kim ${ }^{*}$ (])
}

\begin{abstract}
Thickness-controlled transparent conducting films (TCFs) were fabricated by transfer printing a $100 \mathrm{~nm}$ thick Cu micromesh structure onto poly(vinyl alcohol) (PVA) substrates of different thicknesses $(\sim 50, \sim 80$, and $\sim 120 \mu \mathrm{m})$ to develop a lightweight transparent wearable heater with short response time. The Cu mesh-based TCF fabricated on a $50 \mu \mathrm{m}$ thick PVA substrate exhibited excellent optical and electrical properties with a light transmittance of $86.7 \%$ at $550 \mathrm{~nm}$, sheet resistance of $\sim 10.8 \Omega / \mathrm{sq}$, and figure-of-merit of approximately 236 , which are comparable to commercial indium tin oxide film-based transparent conductors. The remarkable flexibility of the Cu mesh-based TCF was demonstrated through cyclic mechanical bending tests. In addition, the Cu mesh-based TCF with 50 $\mu$ m thick PVA substrate demonstrated a fast Joule heating performance with a thermal response time of $\sim 18.0 \mathrm{~s}$ and a ramping rate of $\sim 3.0^{\circ} \mathrm{C} / \mathrm{s}$ under a driving voltage of $2.5 \mathrm{~V}$. Lastly, the reliable response and recovery characteristics of the Cu mesh/ PVA film-based transparent heater were confirmed through the cyclic power test. We believe that the results of this study is useful in the development of flexible transparent heaters, including lightweight deicing/defogging films, wearable sensors/actuators, and medical thermotherapy pads.
\end{abstract}

Keywords: Wearable transparent heater, Transparent conductor, Metal mesh, Thermal response time, Transfer printing

\section{Introduction}

Transparent heaters (THs) have been studied for multiple potential applications, including smart windows [1, 2], defrosters $[3,4]$, thermochromic displays $[5,6]$, physical/ chemical sensors $[7,8]$, and other advanced heat-generating systems [9-11]. High optical transparency and excellent electrical conductivity are two important factors for high-performance THs. Moreover, this technology is being mainly developed based on the research results of existing transparent conductors with transparent conductive oxides (TCOs), such as indium tin oxide (ITO) and fluorine-doped tin oxide (FTO) films [12]. However,

\footnotetext{
*Correspondence: yoonkap@geri.re.kr

Convergence Materials Research Center, Gumi Electronics

and Information Technology Research Institute (GERI), Cheomdangieop

1-ro, Sandong-myeon, Gumi 39171, Gyeongbuk, Korea
}

owing to their brittle nature, it is extremely difficult to adapt TCO films in the development of next-generation transparent conductors for flexible/wearable $\mathrm{TH}$ applications [11]. Thus, there has been active research on the replacement of commercial TCO films for flexible/wearable THs.

The potential candidate materials for ITO/FTO-free flexible/wearable THs include conductive polymers [6], carbon-based nanomaterials [5, 13, 14], metal-based nano/micro-materials $[3,4]$, and other hybrid materials $[15,16]$. Conductive polymers, such as poly(3,4-ethylen edioxythiophene):poly(styrene sulfonate) (PEDOT:PSS), have outstanding advantages in terms of mechanical flexibility and solution processibility; however, conductive polymers have low electrical conductivity, and poor stability against heat and moisture, thereby limiting their application in high-performance optoelectronic devices 
$[17,18]$. Meanwhile, carbon nanomaterials, such as graphene and carbon nanotubes, have excellent thermal conductivity and flexibility; however, the manufacturing costs for high-quality carbon-based nanomaterials through thermal and plasma chemical vapor deposition techniques are usually expensive [11, 19]. Accordingly, owing to their relatively simple manufacturing process (high productivity) and superior physical properties, such as optical/electrical conductance and mechanical flexibility, the development of metal-based flexible THs with metal nanowires (NWs) and mesh structures have recently garnered considerable attention as an alternative to commercial TCO films $[3,4,9,20]$. Park et al. proposed a stretchable $\mathrm{TH}$ with a stable operation at $\sim 250$ ${ }^{\circ} \mathrm{C}$ using Ag nanofibers on transparent polyimide film, which can be applied to wearable heaters [21]. Ko et al. also reported a stretchable TH using Ag NWs on polydimethylsiloxane substrate with stable operation at $\sim 60{ }^{\circ} \mathrm{C}$, which has potential applications in wearable electronics [22]. Cui et al. reported a flexible $\mathrm{TH}$ using printed $\mathrm{Cu}$ mesh on polyethylene terephthalate substrate with stable operation at $\sim 110{ }^{\circ} \mathrm{C}$ for automotive windshield heating film application [23]. Thus, there has been various research on the fabrication and performance of flexible/ wearable THs based on micro/nano-scale metal materials. Nevertheless, the development of wearable ITO/ FTO-free THs with faster response characteristics needs to be further investigated.

In this study, we introduce a new strategy to develop a lightweight flexible $\mathrm{TH}$ with short response time for wearable thermotherapy and heating systems. A $100 \mathrm{~nm}$ thick conductive $\mathrm{Cu}$ mesh structure with optically transparency and electrically conductivity was fabricated onto poly(vinyl alcohol) (PVA) substratses of different thicknesses $(\sim 50, \sim 80$, and $\sim 120 \mu \mathrm{m})$ through transfer printing method. A lightweight flexible $\mathrm{Cu}$ mehs/PVA film-based transparent conducting film (TCF) based on a $\sim 50 \mu \mathrm{m}$ thick PVA substrate with optical and electrical properties comparable to commercial ITO glass was sucessfully fabricated. Further, the Cu mesh/PVA film-based TCF demonstrated its fast, stable, and reliable performance for TH applications. Finally, for its actual application, the $\mathrm{Cu}$ mesh/PVA film-based TH was attached to a finger and the back of the hand.

\section{Experimental \\ Materials}

Ultraviolet (UV)-curable polyurethane acrylate (PUA) imprint resin (MINS-311RM) and $99.99 \% \mathrm{Cu}$ were purchased from Changsung Sheet Co., Ltd. (Korea) and Taewon Scientific Co. Ltd. (Korea), respectively. And, PVA powders ( $\mathrm{Mw}$ of $85,000-124,000)$ and trichloro( $1 H, 1 H, 2 H, 2 H$-perfluorooctyl)silane (97\%) were purchased from Sigma-Aldrich Inc. (USA).

\section{Optical, electrical, and structural characterization}

The optical transmittance spectra of the prepared $\mathrm{Cu}$ mesh-based TCFs were obtained using a UV-visible near-infrared spectrometer (Cary 5000 UV-vis-NIR, Agilent, USA) with air as the reference. The electrical conductance (sheet resistance) of the $\mathrm{Cu}$ mesh-based TCF was measured using a four-point probe method with a sheet resistivity meter (FPP-2000, DASOL ENG, Korea). The TH structure was analyzed using a fieldemission scanning electron microscope (FE-SEM, Sirion, FEI, USA) and optical microscope (BX51, OLYMPUS, Japan). The weight of the fabricated felxible TCFs were measured using a precision electronic balance (HM-202, A\&D Co. Ltd, Japan). The sheet resistance, optical transmittance, and weight of the TCF were measured at least five times, and then the average value was taken.

\section{Evaluation of the electrothermal performance of the $\mathrm{Cu}$ mesh-based TCFs}

To investigate the Joule heating performance of the $\mathrm{Cu}$ mesh-based TCF, direct current (DC) voltages of $0.5,1.0$, $1.5,2.0$, and $2.5 \mathrm{~V}$ was applied to the TCF through contact with the Ag side. The resulting temperature change was recorded by a direct measurement using a thermocouple (ST-50, RKC Instrument Inc., Japan) mounted on the PVA substrate part without a $\mathrm{Cu}$ mesh. The temperature on the surface of the TH was measured three times and the average value was used. The obtained temperature profile was confirmed using an infrared (IR) camera (Seek Compact, Seek Thermal Inc., USA).

\section{Results and discussion}

In this work, TCFs based on a uniform $\mathrm{Cu}$ mesh structure were fabricated by a tranfer printing method without a lift-off, etching or electroplating process [24]. First, a PUA mold with an engraved micromesh pattern was replicated from a silicon master through a replicate molding method (see Additional file 1: Figure S1). Here, the silicon master used in this work could be prepared by photolithography and dry etching techniques. The surface of the PUA mold was treated with a layer of $1 H, 1 H, 2 H, 2 H$-perfluorooctyl-trichlorosilane to form an anti-sticking layer covering. A thin $\mathrm{Cu}$ layer with a thickness of $100 \mathrm{~nm}$ was deposited on the surface of the PUA mold using an electron-beam evaporator, as shown in Fig. 1a. For this step, $\mathrm{Cu}$ has an evaporation rate of approximately $0.1 \mathrm{~nm} / \mathrm{s}$. Here, the $\mathrm{Cu}$ layer deposited on the PUA mold with the anti-sticking layer was designed to be easily peeled off. A transparent PVA substrate was used as the receiver for the selective transfer of the $\mathrm{Cu}$ mesh layer from the PUA 
(a)
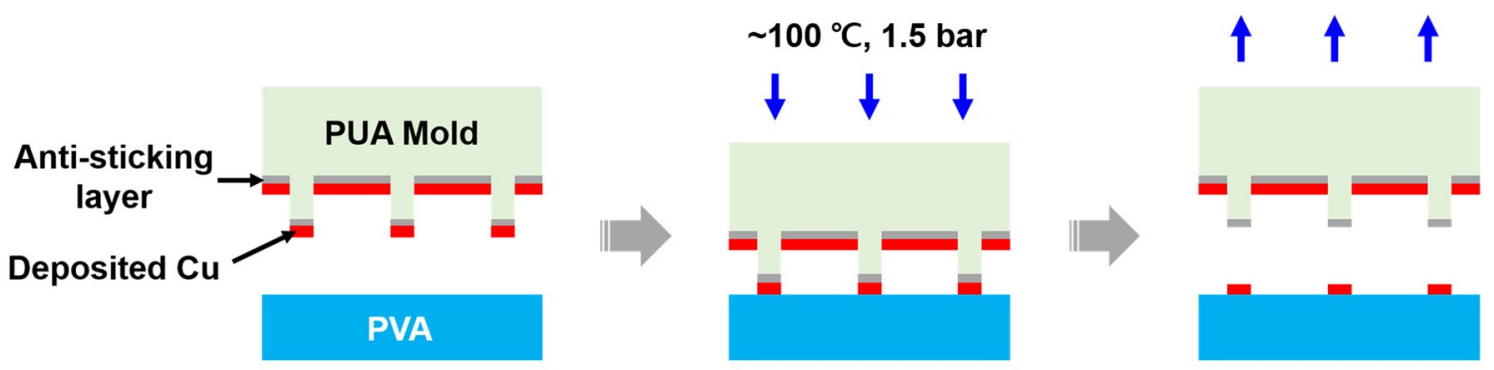

(b)

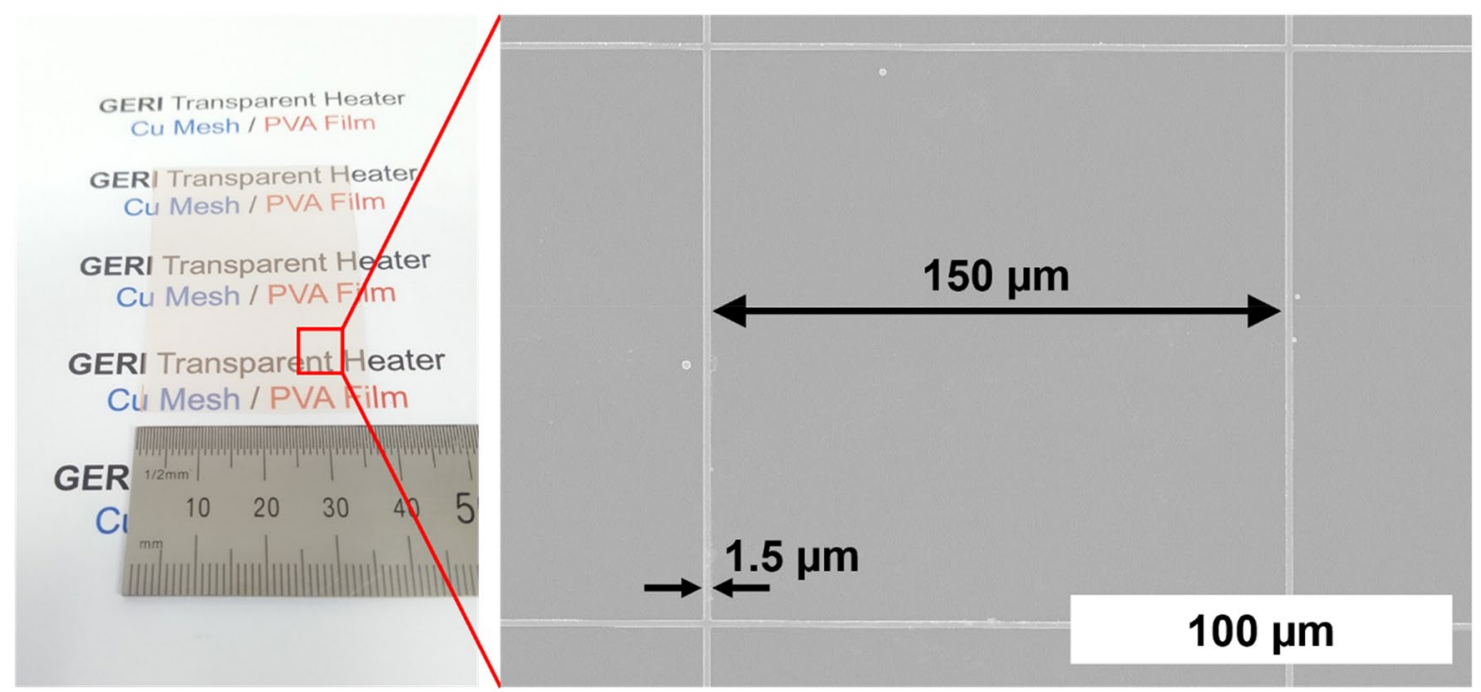

Fig. 1 a Schematic of the transfer printing process. $\mathbf{b}$ Photograph and surface FE-SEM image of the Cu mesh directly printed on the PVA film

mold to fabricate the TH substrate. A 20 wt.\% aqueous PVA solution with viscosity of $\sim 20,000 \mathrm{cP}$ was bar-coated onto a cleaned glass plate and cured in a drying oven at $50{ }^{\circ} \mathrm{C}$ for $24 \mathrm{~h}$, thereby a PVA film with constant thickness was obtained by controlling the gap between the glass plate and blade. After thermal curing, the PVA film was carefully separated from the glass plate. The $\mathrm{Cu}$ thin filmdeposited PUA mold was then placed in contact with the surface of the PVA film. The PUA mold/PVA film was assembled through hot-pressing by applying $\sim 1.5$ bar static pressure at $\sim 100{ }^{\circ} \mathrm{C}$ for $3 \mathrm{~min}$. Subsequently, the PUA mold/PVA film was naturally cooled to room temperature (RT). Finally, a uniform $\mathrm{Cu}$ mesh structure on the PVA film was obtained after peeling the PUA mold. Figure 1b shows a photograph and surface FE-SEM image of the $\mathrm{Cu}$ mesh structure printed on the PVA film. Additional file 1: Figure S2 shows an optical microscope image of the $\mathrm{Cu}$ mesh/PVA film surface observed at a low magnification. A $\mathrm{Cu}$ mesh structure with a line width of $1.5 \mu \mathrm{m}$ and a line spacing of $150 \mu \mathrm{m}$ was sucessfully formed on the PVA film. Further, the optical transparency of the $\mathrm{Cu}$ mesh/PVA film is confirmed.

Figure 2 shows the performance of the $\mathrm{Cu}$ mesh/PVA film as a transparent conductor. As shown in Fig. 2a, a red light-emitting diode (LED) turned on using the $\sim 50 \mu \mathrm{m}$ thick $\mathrm{Cu}$ mesh/PVA film-based TCF. The as-prepared $\mathrm{Cu}$ mesh/PVA film-based TCF exhibited an optical transmittance of $86.7 \%$ at $550 \mathrm{~nm}$, average transmittance of $\sim 85.0 \%$ over the entire visible range (see Additional file 1: Figure S3), and average sheet resistance of $\sim 10.0 \Omega / \mathrm{sq}$ (see Additional file 1: Figure $\mathrm{S} 4)$. The optical transmittance at $550 \mathrm{~nm}$, sheet resistance, and figure-of-merit (FOM) of the commercial ITO glass and $\mathrm{Cu}$ mesh/PVA film-based TCFs with various thicknesses are summarized in Table 1. The FOM value is calculated as the ratio of the electrical conductance $\left(\sigma_{\mathrm{dc}}\right)$ to the optical conductance $\left(\sigma_{\mathrm{opt}}\right)$, following the equation: [24] 
(a)

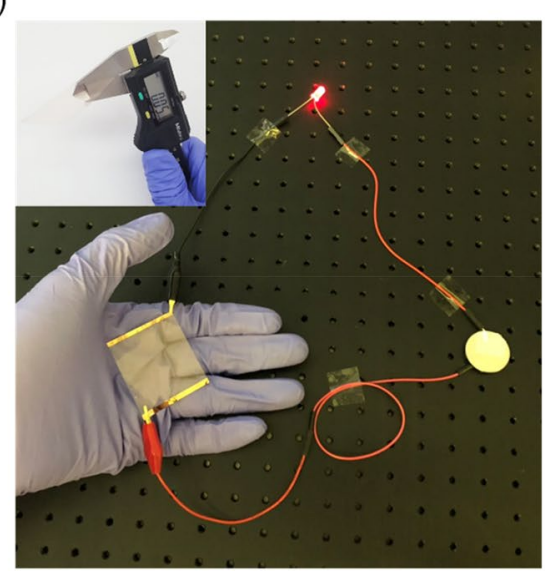

(b)

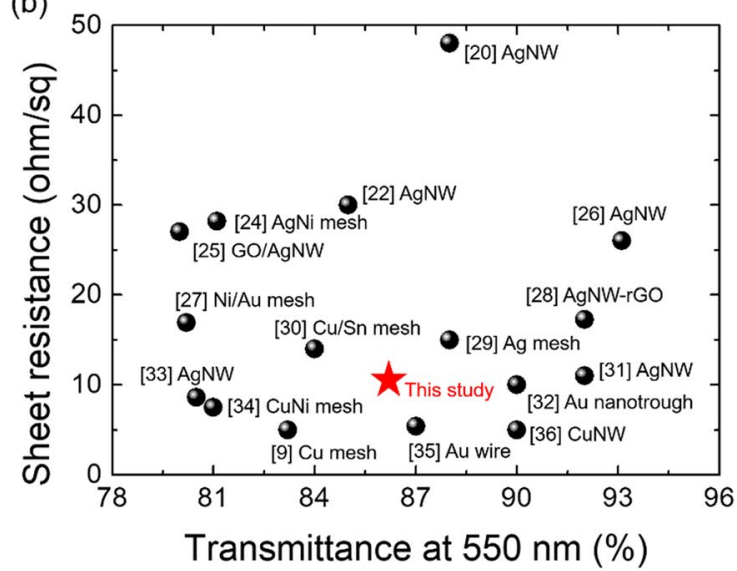

Fig. 2 a Digital photograph of the Cu mesh/PVA film $(45 \mathrm{~mm} \times 45 \mathrm{~mm}$ ) with $50 \mu \mathrm{m}$ thick PVA substrate as a transparent conductor in an electronic circuit connected to a LED. $\mathbf{b}$ Comparison of the optical transmittance and sheet resistance of the Cu mesh/PVA film with 50 $\mu \mathrm{m}$ thick PVA substrate fabricated this study, and those of previously reported metal-based transparent conductors. The numbers in the square brackets indicate the cited references

Table 1 Transmittance at $550 \mathrm{~nm}$, average sheet resistance, and FOM of the commecial ITO glass and fabricated Cu mesh/PVA films with various substrate thicknesses

\begin{tabular}{|c|c|c|c|}
\hline Sample & $\begin{array}{l}\text { Transmittance } \\
\text { at } 550 \mathrm{~nm} \\
(\%)\end{array}$ & $\begin{array}{l}\text { Sheet resistance } \\
\text { (ohm/sq) }\end{array}$ & FOM \\
\hline $\begin{array}{l}\sim 50 \mu \mathrm{m} \text { thick } \\
\text { Cu mesh/PVA film }\end{array}$ & 86.7 & $\sim 10.8$ & 236.1 \\
\hline $\begin{array}{l}\sim 80 \mu \mathrm{m} \text { thick } \\
\text { Cu mesh/PVA film }\end{array}$ & 86.5 & & 232.0 \\
\hline $\begin{array}{l}\sim 120 \mu \mathrm{m} \text { thick } \\
\text { Cu mesh/PVA film }\end{array}$ & 86.4 & & 230.2 \\
\hline $\begin{array}{l}\text { Commercial ITO glass } \\
(0.7 \mathrm{~mm})\end{array}$ & 85.6 & $\sim 10.0$ & 235.6 \\
\hline
\end{tabular}

$$
\sigma_{\mathrm{dc}} / \sigma_{\mathrm{opt}}=Z_{0} / 2 R_{\mathrm{S}}\left(T^{-1 / 2}-1\right)
$$

where $R_{\mathrm{S}}$ and $T$ are the measured sheet resistance and the optical transmittance at $550 \mathrm{~nm}$, respectively, and $Z_{0}$ is the impedance at free space $(377 \Omega)$. As shown in the Table 1 , the $\mathrm{Cu}$ mesh/PVA film with $\sim 50 \mu \mathrm{m}$ thick PVA substrate has an FOM value of 236.1, which is similar to that of commercial ITO glass (235.6). The weights of the $\mathrm{Cu}$ mesh-based TCFs fabricated on $\sim 50, \sim 80$, and $\sim 120 \mu \mathrm{m}$ thick PVA films were measured to be 27.8 , 42.7 , and $65.9 \mathrm{mg}$, respectively. The weight per unit area of the $\mathrm{Cu}$ mesh-based TCF with $\sim 50 \mu \mathrm{m}$ PVA substrate was approximately $0.0695 \mathrm{mg} / \mathrm{mm}^{2}$. As seen in Fig. 2b, the optical and electrical conductance of the $\mathrm{Cu}$ mesh/ PVA film-based TCF with $\sim 50 \mu \mathrm{m}$ thick PVA substrate was comparable to that of other metal-based transparent conductors [9, 20, 22, 24-36].

To apply the fabricated Cu mesh/PVA film-based TCF to flexible/wearable electronic devices, the change in the current-voltage relationship under bending should be investigated. Thus, the current of the $\mathrm{Cu}$ mesh/PVA filmbased TCF with $\sim 50 \mu \mathrm{m}$ thick PVA substrate was measured with different input voltages with its flat and bent state. As shown in Fig. 3a, the current steadily increased up to $288 \mathrm{~mA}$ at an applied voltage of $3.0 \mathrm{~V}$ in the flat state. In contrast, when the $\mathrm{Cu}$ mesh/PVA film was bent with an outside bending radius of $5 \mathrm{~mm}$, the current slightly decreased to $277 \mathrm{~mA}$ at $3.0 \mathrm{~V}$. The slight decrease in the current at a relatively high input voltage range $(2.0-3.0 \mathrm{~V})$ is mainly attributed to the decrease in the local connectivity between the evaporated $\mathrm{Cu}$ particles induced by the bending stress.

Figure $3 \mathrm{~b}$ shows the changes in the sheet resistance of the $\mathrm{Cu}$ mesh/PVA film and ITO/PVA film-based TCFs fabricated with the same thickness $(\sim 50 \mu \mathrm{m})$ as the bending radius decreases. The sheet resistance of the ITO/ PVA film-based TCF with an initial sheet resistance of $\sim 30 \Omega$ /sq significantly increased when the bending radii were less than $10 \mathrm{~mm}$ due to the increased brittleness of ITO thin film [29]. The cracks formed on the surface of the ITO film could be confirmed after the mechanical bending test, as shown in the optical microscope image inserted in Fig. 3b. In contrast to the ITO/ PVA film-based TCF, there were no changes observed in the initial sheet resistance $(\sim 11 \Omega / \mathrm{sq})$ of the $\mathrm{Cu}$ mesh/ PVA film-based TCF even at a bending radius as small as $4 \mathrm{~mm}$. Figure $3 \mathrm{c}$ shows the changes in the sheet resistance 
(a)

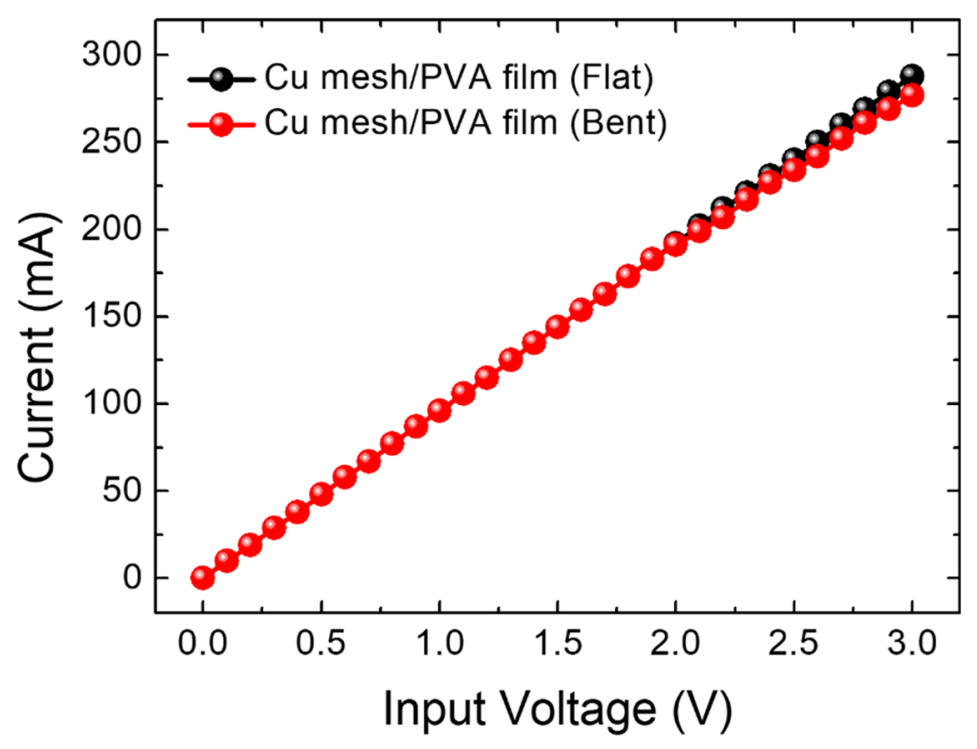

(b)

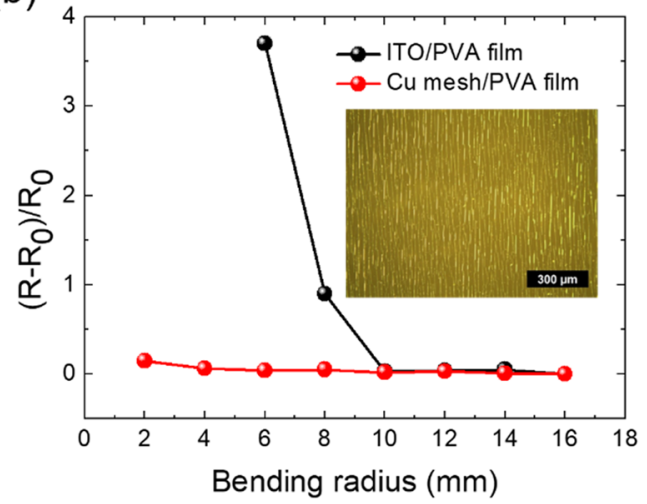

(c)

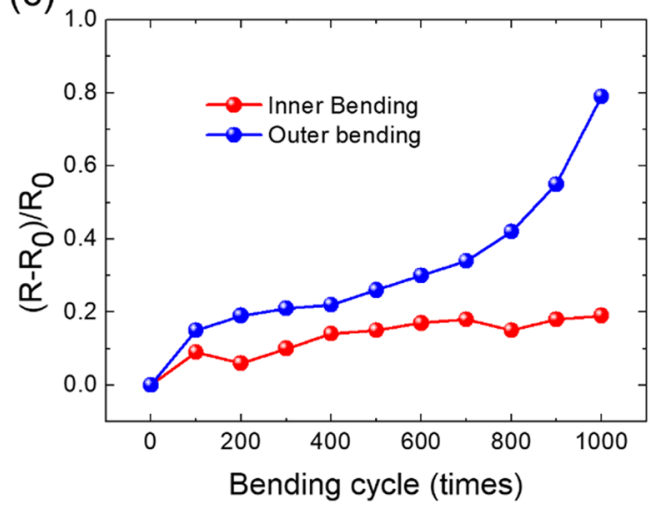

Fig. 3 a Current-voltage relationship of Cu mesh/PVA film ( $45 \mathrm{~mm} \times 45 \mathrm{~mm}$ ) in its flat and bent state with a bending radius of $5 \mathrm{~mm}$. $\mathbf{b}$ Changes in the sheet resistance of the Cu mesh/PVA film and ITO/PVA films as a function of the bending radius. The inset shows an optical microscope image of the ITO film after the bending test. c Changes in the sheet resistance of the Cu mesh/PVA film with 50 $\mu \mathrm{m}$ thick PVA substrate with respect to the bending cycles at a fixed bending radius of $4 \mathrm{~mm}$

with the increase of the bending cycles for the outward and inward bending fatigue tests of the $\mathrm{Cu}$ mesh/PVA film-based TCF with $\sim 50 \mu \mathrm{m}$ thick PVA substrate at a fixed bending radius of $4 \mathrm{~mm}$. After 1,000 cycles, the sheet resistance of the $\mathrm{Cu}$ mesh/PVA film-based TCF marginally increased to $\sim 20 \%$ for the inner bending tests, whereas it increased by $\sim 80 \%$ for the outer bending tests. These experimental results indicate that the uniform $\mathrm{Cu}$ mesh structure is more vulnerable to failure under external bending stress than internal bending stress.

The excellent flexibility of the $\mathrm{Cu}$ mesh/PVA filmbased TCF was further demonstrated by lighting a red LED using the fabricated $\mathrm{Cu}$ mesh/PVA film-based TCF as the flexible transparent conductor, as shown in Fig. 4.
Particularly, there are no noticeable changes in the LED brightness before and after bending the TCF.

Figure $5 \mathrm{a}$ shows the time-dependent temperature of the $\mathrm{Cu}$ mesh/PVA film as a $\mathrm{TH}$ with a sheet resistance of $\sim 11.0 \Omega / \mathrm{sq}$. By applying different bias voltages $(0.5-$ $2.5 \mathrm{~V})$, the temperature of the $\mathrm{Cu}$ mesh/PVA film-based $\mathrm{TH}$ rapidly increased from $\mathrm{RT}$ to saturated values until the thermal equilibrium was achieved. The temperature of the $\mathrm{TH}$ rapidly increased with respect to the driving voltage. At a driving voltage of $2.5 \mathrm{~V}$, the temperature of the $\mathrm{TH}$ reached $\sim 85.0{ }^{\circ} \mathrm{C}$. The heat generation of the $\mathrm{Cu}$ mesh/PVA film-based TH first occurred through Joule heating. The generated heat subsequently dissipated through conduction in the substrate, air convection, and 

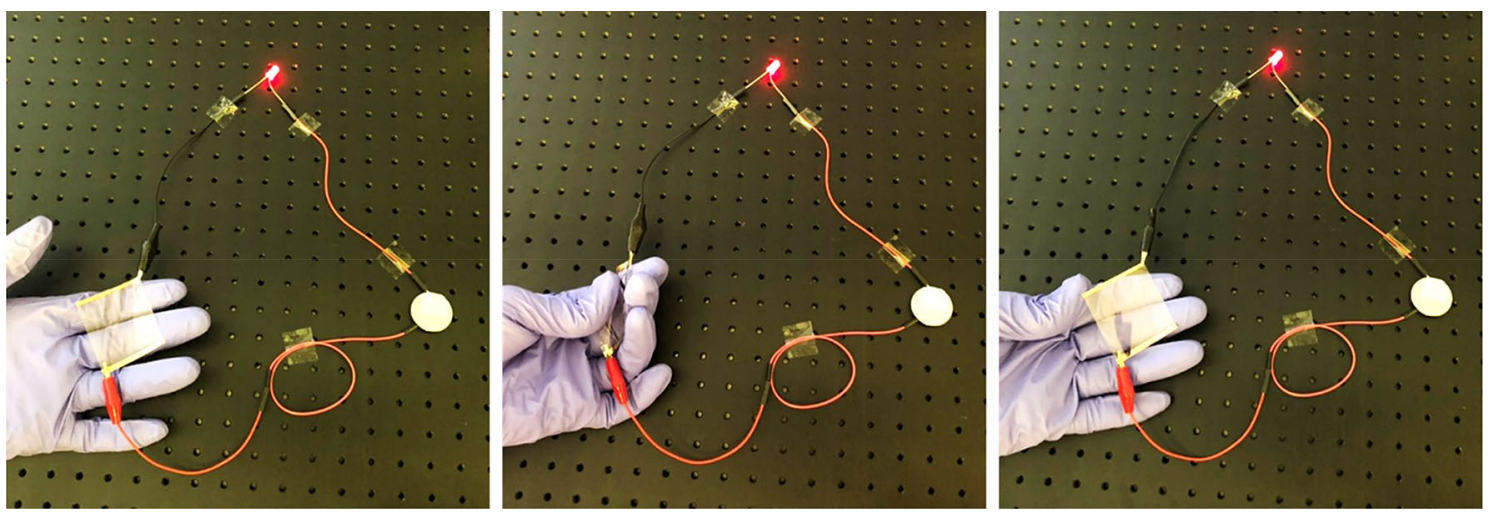

Fig. 4 Photographs of the $45 \mathrm{~mm} \times 45 \mathrm{~mm}$ Cu mesh/PVA film used as the transparent electrode to power a red LED before and after manual bending

radiation [9]. When the applied voltage was cut off, the temperature of the $\mathrm{TH}$ decreased to $\mathrm{RT}$ in $\sim 60 \mathrm{~s}$. Figure $5 \mathrm{~b}$ shows the time-temperature curves of the $\mathrm{TH}$ with different PVA film thicknesses at a constant input voltage of $2.5 \mathrm{~V}$. The response time, which is defined as the time required to reach $90 \%$ of the steady-state temperature during operation, of the $\mathrm{Cu}$ mesh/PVA filmbased THs with a PVA film with thickness of $\sim 50, \sim 80$, and $\sim 120 \mu \mathrm{m}$ were $18.0,21.5$, and $23.5 \mathrm{~s}$, respectively. Here, the average response time of the THs with various PVA film thickness was reproducible with a relative standard deviation of only $2.1 \%$. And, the response time of the $\mathrm{TH}$ based on $\mathrm{Cu}$ mesh/PVA film with a thickness of $\sim 50 \mu \mathrm{m}$ is much faster than that of the flexible TH reported so far (see Additional file 1: Table S1) [Additional file 1: S1-5, 23, 26]. The thinner $\mathrm{Cu}$ mesh/ PVA film $\mathrm{TH}$ exhibited shorter thermal response time and faster ramp rate (see Table 2). The decrease in the heater response time due to the decrease in the thickness of the heater substrate (PVA film) could be explained as follows. For a $\mathrm{Cu}$ mesh/PVA film-based $\mathrm{TH}$ at a given driving voltage, the heating (ramping) rate and saturated temperature depend on the thermal properties of the heating element ( $\mathrm{Cu}$ mesh structure) and the heater substrate (PVA film). Generally, response time is related to the time constant $(\tau)$ of the transient thermal response depicted as: [16]

$$
\tau=C / h A
$$

where $C$ refers to the heat capacity, $h$ is the heat transfer coefficient, and $A$ is the surface area. In this study, the heating element $(\mathrm{Cu}$ mesh structure) thickness of $\sim 100 \mathrm{~nm}$ can be deemed negligible compared to the thickness of the heater substrate (PVA film), which is in the range of $50-120 \mu \mathrm{m}$. Therefore, the heat capacity $(C)$ of the $\mathrm{Cu}$ mesh structure could be neglected and that of the PVA film dominates the transient process of the electrothermal response. Thus, $\tau$ can be rewritten as Eq. (3).

$$
\tau=C / h A=c m / h A=\rho d c / h
$$

where $c, m, \rho$, and $d$ are the specific heat capacity, mass, density, and thickness of the PVA film, respectively. Therefore, the response time of the $\mathrm{Cu}$ mesh/PVA filmbased $\mathrm{TH}$ could be reduced by reducing the thickness of the heater substrate (PVA film).

The repeatability of the heat generation of the $\mathrm{TH}$ was investigated by a cyclic test of $10 \mathrm{on} / \mathrm{off}$ cycles. As shown in Fig. $5 \mathrm{c}$ and Table 3, there were no significant changes in the thermal response/recovery characteristics of the $\mathrm{Cu}$ mesh/PVA film-based TH during the cyclic test.

Joule heating demonstrated a self-annealing effect on the $\mathrm{Cu}$ mesh structure. As shown in Fig. 6, the sheet resistance of the $\mathrm{Cu}$ mesh/PVA film-based TH exponentially dropped from $\sim 10.9 \mathrm{ohnm} / \mathrm{sq}$ to $\sim 8.9 \Omega / \mathrm{sq}$ (18.3\% decresae) after self-annealing at $\sim 85{ }^{\circ} \mathrm{C}$ for $3 \mathrm{~h}$. The decrease in the sheet resistance is attributed to the increased electrical connectivity between the $\mathrm{Cu}$ particles after Joule heating (self-annealing) [35]. Hence, the sheet resistance of the Cu mesh/PVA film-based TH can be effectively reduced through the self-annealing process, thereby reducing the power consumption and improving the heat generation performance of the $\mathrm{TH}$.

Figure 7, Additional file 1: Figures S5, and S6 show the operation of the $\mathrm{Cu}$ mesh/PVA film-based THs with various shapes and sizes. When the $\mathrm{TH}$ was attached to curved surfaces, such as a round-bottom flask and finger (see the Additional file 1: Figure S5 and S6, respectively), the $\mathrm{TH}$ retained its normal functions. In addition, the $\mathrm{TH}$ fixed on the back of the hand opreated normally when the fist was clenched and opened, as shown in the Fig. 7. These results indicate the applicability of the fabricated $\mathrm{Cu}$ mesh/PVA film-based TCF as a flexible/wearable TH. 


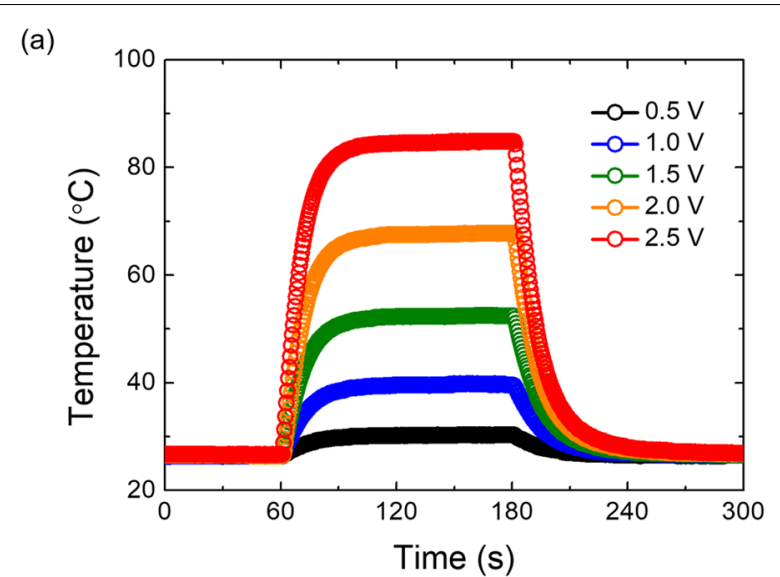

(b)

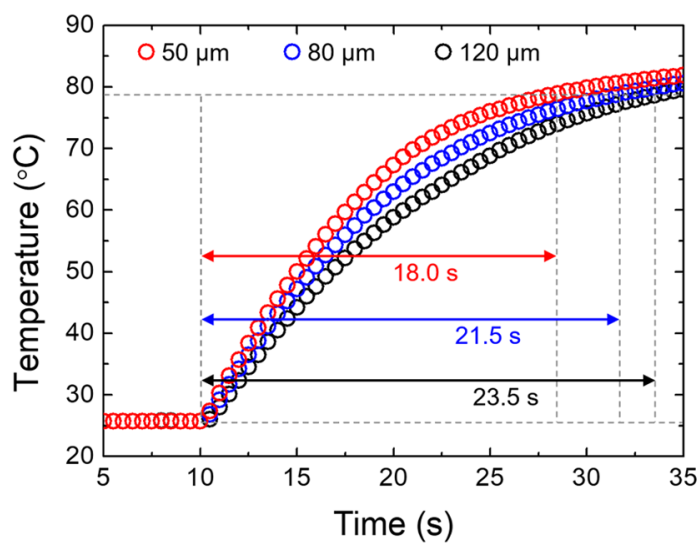

(c)

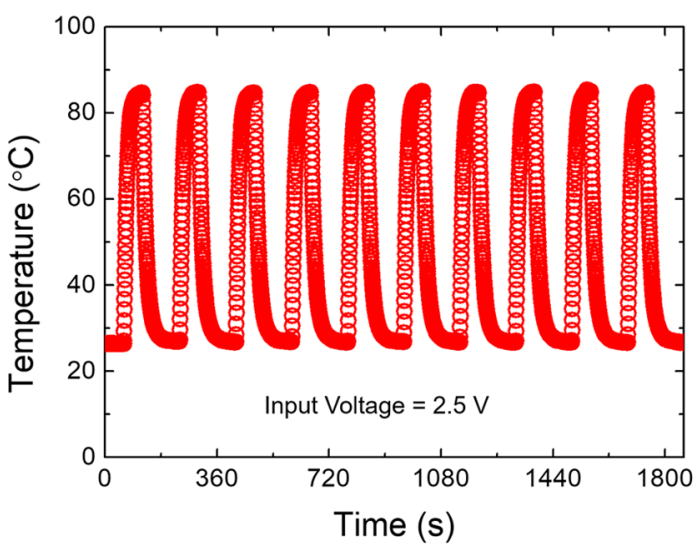

Fig. 5 a Heat generation performance of the Cu mesh/PVA film heater $(20 \mathrm{~mm} \times 20 \mathrm{~mm})$ as a function of time at an applied voltage of $0.5,1.0,1.5,2.0$, and $2.5 \mathrm{~V}$. $\mathbf{b}$ Time-temperature curves of the $\mathrm{Cu}$ mesh/PVA film TH of different PVA substrate thicknesses. The time provided in the graphs indicate the response time of the THs. c Results of the cyclic test of the heat generation of the Cu mesh/PVA film heater with an applied voltage of $2.5 \mathrm{~V}$
Table 2 Comparison of the performances of the Cu mesh/PVA film heaters fabricated with various PVA film thicknesses

\begin{tabular}{lllll}
\hline Thickness $(\boldsymbol{\mu m})$ & $\begin{array}{l}\mathbf{R}_{\mathbf{s}} \\
(\mathbf{o h m} / \mathbf{s q})\end{array}$ & $\begin{array}{l}\text { Max. Temp. } \\
\text { at 2.5 V }\left({ }^{\circ} \mathrm{C}\right)\end{array}$ & $\begin{array}{l}\text { Response } \\
\text { time }(\mathbf{s})\end{array}$ & $\begin{array}{l}\text { Ramping } \\
\text { rate }\left({ }^{\circ} \mathrm{C} / \mathbf{s}\right)\end{array}$ \\
\hline 50 & $\sim 11.0$ & 84.7 & 18.0 & 2.94 \\
80 & & 84.5 & 21.5 & 2.46 \\
120 & & 84.4 & 23.5 & 2.25 \\
\hline
\end{tabular}

Table 3 Changes in the performance of the Cu mesh/PVA filmbased TH during the cyclic test

\begin{tabular}{lllll}
\hline Cycle No & $\begin{array}{l}\mathbf{R}_{\mathbf{s}} \\
\text { (ohm/sq) }\end{array}$ & $\begin{array}{l}\text { Max. Temp } \\
\left({ }^{\circ} \mathrm{C}\right)\end{array}$ & $\begin{array}{l}\text { Response time } \\
\text { (s) }\end{array}$ & $\begin{array}{l}\text { Min. Temp } \\
\left({ }^{\circ} \mathrm{C}\right)\end{array}$ \\
\hline 0 & 11.0 & - & - & - \\
1 & 10.8 & 84.6 & 18.0 & 26.9 \\
2 & 10.8 & 84.7 & 18.0 & 26.7 \\
3 & 10.9 & 84.5 & 17.5 & 26.8 \\
4 & 10.8 & 84.7 & 18.0 & 26.7 \\
5 & 10.8 & 84.8 & 18.5 & 26.8 \\
6 & 10.8 & 84.9 & 18.5 & 26.8 \\
7 & 10.9 & 84.8 & 18.0 & 26.7 \\
8 & 11.0 & 84.9 & 18.5 & 26.8 \\
9 & 10.8 & 84.9 & 18.5 & 26.9 \\
10 & 10.9 & 84.6 & 18.0 & 26.8 \\
\hline
\end{tabular}

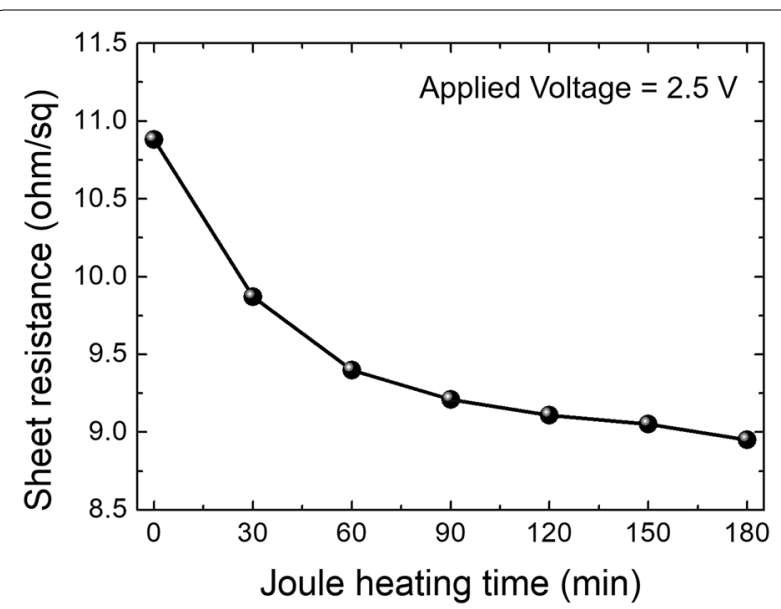

Fig. 6 Change in the sheet resistance of the Cu mesh/PVA film with respect to the thermal treatment time by Joule heating

Taken together, the proposed method has the advantage that there are no additional processing techniques such as lift-off, etching, or electroplating, compared with the previous studies on the fabrication of highperformance flexible/wearable THs [23, 30, 32, 35]. In addition, it was found that the thermal response time of 

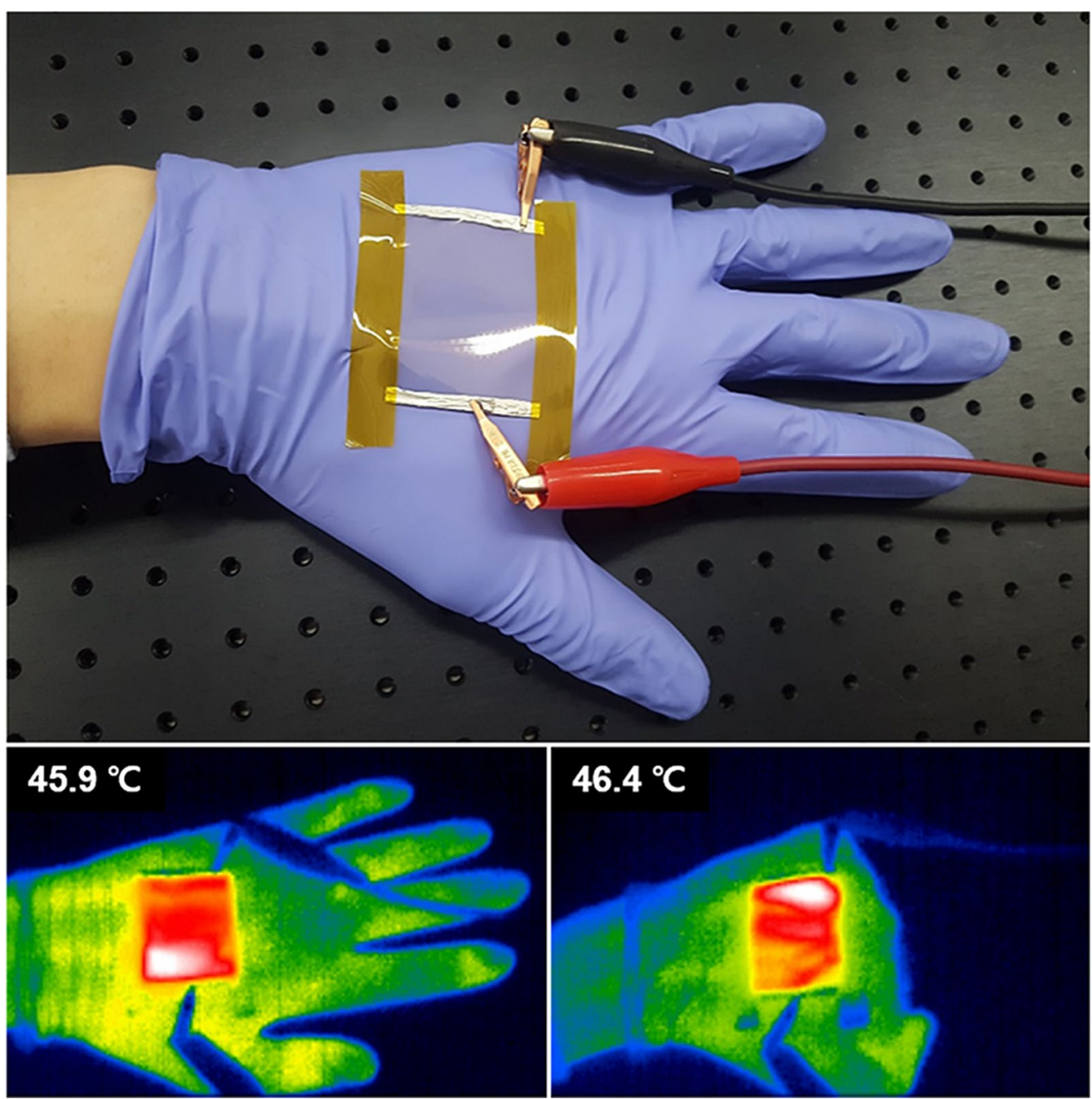

Fig. 7 Photograph and IR thermal images of the operation of the Cu mesh/PVA film-based TH ( $45 \mathrm{~mm} \times 45 \mathrm{~mm})$ attached to the back of the hand

the heater was shortened in proportion to the decrease in the thickness of the heater substrate.

\section{Conclusion}

In summary, we developed a lightweight flexible TCF by transfer printing a $100 \mathrm{~nm}$ thick $\mathrm{Cu}$ mesh structure onto PVA films of various thicknesses for application in wearable heaters. A Cu mesh-based lightweight TCF fabricated on a $\sim 50 \mu \mathrm{m}$ thick PVA substrate demonstrated optical and electrical properties comparable to those of commercial ITO glass. In addition, the $\mathrm{Cu}$ mesh/PVA film-based TCF exhibited superior mechanical flexibility compared to the ITO thin film sputtered on the same substrate. The TCF demonstrated its rapid Joule heating behavior with a response time of $\sim 18.0 \mathrm{~s}$ and a ramping rate of $\sim 3.0{ }^{\circ} \mathrm{C} / \mathrm{s}$ at a driving voltage of $2.5 \mathrm{~V}$. The reliable response and recovery characteristics of the $\mathrm{Cu}$ mesh/PVA film-based
TH were confirmed through the cyclic tests. Lastly, the lightweight $\mathrm{TH}$ attached to a human hand or round bottom flask successfully retained its normal functions. Based on the above research results, we expect that the $\mathrm{Cu}$ mesh-based lightweight TCF could be used as an ITO/FTO-free electrode/heater for advanced wearable electronic devices.

\section{Abbreviations}

TCF: Transparent conducting film; PVA: Poly(vinyl alcohol); TH: Transparent heater; TCO: Transparent conductive oxide; ITO: Indium tin oxide; FTO: Fluorine-doped tin oxide; PEDOT:PSS: Poly(3,4-ethylenedioxythiophene):poly(styr ene sulfonate); NW: Nanowire; UV: Ultraviolet; PUA: Polyurethane acrylate; DC: Direct current; IR: Infrared; RT: Room temperature; LED: Light-emitting diode; FOM: Figure-of-merit; $\sigma_{\mathrm{dc}}$ : Electrical conductance; $\sigma_{\mathrm{opt}}$ : Optical conductance; $R_{\mathrm{S}}$ : Sheet resistance; $T$ : Optical transmittance at $550 \mathrm{~nm} ; Z_{0}:$ Impedance at free space; $\tau$ : Time constant; $C$ : Heat capacity; $h$ : Heat transfer coefficient; $A$ Surface area; $\boldsymbol{C}$ : Specific heat capacity; $\boldsymbol{M}$ : Mass; $\rho$ : Density; $d$ : Thickness film. 


\section{Supplementary Information}

The online version contains supplementary material available at https://doi. org/10.1186/s40486-021-00132-5.

Additional file 1. Fabrication, optical and electrical properties, and heater performances of the Cu mesh/PVA film-based TCF.

\section{Acknowledgements}

This work was supported by the Technology Innovation Program (20006408) funded by the Ministry of Trade, Industry \& Energy (MOTIE, Korea) and the Korea Innovation Foundation (INNOPOLIS) grant funded by the Korea government (MSIT) (2020-DD-UP-0278).

\section{Authors' contributions}

HK conducted the main experiment. YK supervised the project. All authors read and approved the final manuscript.

\section{Funding}

Technology Innovation Program (20006408).

Korea government (MSIT) (2020-DD-UP-0278).

\section{Availability of data and materials}

All data generated or analyzed during in this study are included in this published article and the supplementary information.

\section{Declarations}

Ethics approval and consent to participate Not applicable.

\section{Consent for publication}

Not applicable.

\section{Competing interests}

The authors declare no competing interest (both financial and non-financial).

\section{Received: 4 Auqust 2021 Accepted: 14 October 2021}

Published online: 25 October 2021

\section{References}

1. Patel M, Seo JH, Kim S et al (2021) Photovoltaic-driven transparent heater of $\mathrm{ZnO}$-coated silver nanowire networks for self-functional remote power system. J Power Sources 491:229578. https://doi.org/10.1016/j.jpowsour. 2021.229578

2. Huang WR, He Z, Wang JL et al (2019) Mass production of nanowireNylon flexible transparent smart windows for $\mathrm{PM}_{25}$ capture. iScience 12:333-341. https://doi.org/10.1016/j.isci.2019.01.014

3. Kim HJ, Kim Y, Jeong JH et al (2015) A cupronickel-based micromesh film for use as a high-performance and low-voltage transparent heater. J. Mater. Chem. A 3:16621-16626. https://doi.org/10.1039/C5TA03348A

4. Veeramuthu L, Chen BY, Tsai CY et al (2019) Novel stretchable thermochromic transparent heaters designed for smart window defroster applications by spray coating silver nanowire. RSC Adv 9:35786-35796. https://doi.org/10.1039/C9RA06508C

5. Xie H, Cui K, Cui L et al (2020) $\mathrm{H}_{2} \mathrm{O}$-etchant-promoted synthesis of highquality graphene on glass and its application in see-through thermochromic displays. Small 16:1905485. https://doi.org/10.1002/smll.20190 5485

6. Gueye MN, Carella A, Demadrille R et al (2017) All-polymeric flexible transparent heaters. ACS Appl Mater Interfaces 9:27250-27256. https:// doi.org/10.1021/acsami.7b08578

7. Jo HS, An S, Kwon HJ et al (2020) Transparent body-attachable multifunctional pressure, thermal, and proximity sensor and heater. Sci Rep 10:2701. https://doi.org/10.1038/s41598-020-59450-0
8. Walia S, Gupta R, Rao KDM et al (2016) Transparent Pd wire networkbased areal hydrogen sensor with inherent Joule heater. ACS Appl Mater Interfaces 8:23419-23424. https://doi.org/10.1021/acsami.6b08275

9. Kim HJ, Kim JH, Kim Y (2020) A fluoropolymer-coated nanometer-thick Cu mesh film for a robust and hydrophobic transparent heater. ACS Appl Nano Mater 9:8672-8678. https://doi.org/10.1021/acsanm.0c01404

10. Park J, Lee S, Kim Dl et al (2019) Evaporation-rate control of water droplets on flexible transparent heater for sensor application. Sensors 19:4918. https://doi.org/10.3390/s19224918

11. Kim HJ, Choi DI, Lee S et al (2021) Quick thermal response-transparentwearable heater based on copper mesh/poly(vinyl alcohol) film. Adv Eng Mater. https://doi.org/10.1002/adem.202100395

12. Park JW, Kang BH, Kim HJ (2020) A review of low-temperature solutionprocessed metal oxide thin-film transistors for flexible electronics. Adv Funct Mater 30:1904632. https://doi.org/10.1002/adfm.201904632

13. Bae JJ, Lim SC, Han GH et al (2012) Heat dissipation of transparent graphene defoggers. Adv Funct Mater 22:4819-4826. https://doi.org/10 1002/adfm.201201155

14. Kim Y, Lee HR, Saito T et al (2017) Ultra-thin and high-response transparent and flexible heater based on carbon nanotube film. Appl Phys Lett 110:153301. https://doi.org/10.1063/1.4978596

15. Kang TW, Kim SH, Kim CH et al (2017) Flexible polymer/metal/polymer and polymer/metal/inorganic trilayer transparent conducting thin film heaters with highly hydrophobic surface. ACS Appl Mater Interfaces 9:33129-33136. https://doi.org/10.1021/acsami.7b09837

16. Ji S, He W, Wang K et al (2014) Thermal response of transparent silver nanowire/PEDOT:PSS film heaters. Small 23:4951-4960. https://doi.org/ 10.1002/smll.201401690

17. Fan X, Nie W, Tsai H et al (2019) PEDOT:PSS for flexible and stretchable electronics: modifications, strategies, and applications. Adv Sci 6:1900813. https://doi.org/10.1002/advs.201900813

18. Zhu Z, Yang G, Li R et al (2017) Photopatternable PEDOT:PSS/PEG hybrid thin film with moisture stability and sensitivity. Microsyst Nanoeng 3:17004. https://doi.org/10.1038/micronano.2017.4

19. Wu J, Agrawal M, Becerril HA et al (2010) Organic light-emitting diodes on solution-processed graphene transparent electrodes. ACS Nano 4:43-48. https://doi.org/10.1021/nn900728d

20. Hong $\mathrm{CH}$, Oh SK, Kim TK et al (2016) Electron beam irradiated silver nanowires for a highly transparent heater. Sci Rep 5:17716. https://doi. org/10.1038/srep17716

21. Jang J, Hyun BG, Ji S et al (2017) Rapid production of large-area, transparent and stretchable electrodes using metal nanofibers as wirelessly operated wearable heaters. NPG Asia Mater 9:e432. https://doi.org/10.1038/ am.2017.172

22. Hong S, Lee H, Lee J et al (2015) Highly stretchable and transparent metal nanowire heater for wearable electronics applications. Adv Mater 27:4744-4751. https://doi.org/10.1002/adma.201500917

23. Chen X, Nie S, Guo W et al (2019) Printable high-aspect ratio and highresolution Cu grid flexible transparent conductive film with figure of merit over 80000. Adv Electron Mater 5:1800991. https://doi.org/10.1002/ aelm.201800991

24. Kim HJ, Lee SH, Lee J et al (2014) High-durable AgNi nanomesh film for a transparent conducting electrode. Small 10:3767-3774. https://doi.org/ 10.1002/smll.201400911

25. Zhang $X$, Yan $X$, Chen J et al (2014) Large-size graphene microsheets as a protective layer for transparent conductive silver nanowire film heaters. Carbon 69:437-443. https://doi.org/10.1016/j.carbon.2013.12.046

26. Lan W, Chen Y, Yang Z et al (2017) Ultraflexible transparent film heater made of Ag nanowire/PVA composite for rapid-response thermotherapy pads. ACS Appl Mater Interfaces 9(6644):6651. https://doi.org/10.1021/ acsami.6b16853

27. Chen D, Fan G, Zhang H et al (2019) Efficient Ni/Au mesh transparent electrodes for ITO-free planar Perovskite solar cells. Nanomaterials 9:932. https://doi.org/10.3390/nano9070932

28. Ahn Y, Jeong Y, Lee Y (2012) Improved thermal oxidation stability of solution-processable silver nanowire transparent electrode by reduced graphene oxide. ACS Appl Mater Interfaces 4:6410-6414. https://doi.org/ 10.1021/am301913w

29. Song M, Kim HJ, Kim CS et al (2015) ITO-free highly bendable and efficient organic solar cells with Ag nanomesh/ZnO hybrid electrodes. J Mater Chem A 3:65-70. https://doi.org/10.1039/C4TA05294C 
30. Chen X, Wu X, Shao S et al (2017) Hybrid printing metal-mesh transparent conductive films with lower energy photonically sintered copper/tin ink. Sci Rep 7:13239. https://doi.org/10.1038/s41598-017-13617-4

31. Wang S, Zhang X, Zhao W (2013) Flexible, transparent, and conductive film based on random networks of Ag nanowires. J Nanomater 2013:456098. https://doi.org/10.1155/2013/456098

32. Wu H, Kong D, Ruan Z et al (2013) A transparent electrode based on a metal nanothrough network. Nat Nanotechnol 8:421-425. https://doi. org/10.1038/nnano.2013.84

33. Tokuno T, Nogi M, Karakawa M et al (2011) Fabrication of silver nanowire transparent electrodes at room temperature. Nano Res 4:1215-1222. https://doi.org/10.1007/s12274-011-0172-3

34. Kim HJ, Song M, Jeong JH et al (2016) Highly efficient and stable cupronickel nanomesh electrode for flexible organic photovoltaic devices. J Power Sources 331:22-25. https://doi.org/10.1016/j.jpowsour.2016.09.024
35. Rao KDM, Kulkarni GU (2014) A highly crystalline single Au wire network as a high temperature transparent heater. Nanoscale 6:5645-5651. https://doi.org/10.1039/C4NR00869C

36. Nikzad MJ, Mohamadbeigi N, Sadrnezhaad SK et al (2019) Fabrication of a highly flexible and affordable transparent electrode by aligned U-shaped copper nanowires using a new electrospinning collector with convenient transferability. ACS Omega 4:21260-21266. https://doi.org/10.1021/ acsomega.9b02760

\section{Publisher's Note}

Springer Nature remains neutral with regard to jurisdictional claims in published maps and institutional affiliations.

\section{Submit your manuscript to a SpringerOpen ${ }^{\circ}$ journal and benefit from:}

- Convenient online submission

- Rigorous peer review

- Open access: articles freely available online

- High visibility within the field

- Retaining the copyright to your article

Submit your next manuscript at $\boldsymbol{\nabla}$ springeropen.com 